\title{
Vicente de la Fuente y Bueno, prototipo de historiador e investigador decimonónico
}

\author{
Pablo RAMÍREZ JEREZ \\ Real Academia de Ciencias Morales y Políticas. Biblioteca \\ biblioteca@racmyp.es
}

Recibido: Septiembre 2014

Aceptado: Octubre 2014

\begin{abstract}
Resumen: El presente artículo analiza la figura de Vicente de la Fuente y Bueno, teólogo, apologista católico, catedrático, académico y uno de los principales historiadores españoles del siglo XIX, persona de enorme prestigio en los círculos académicos y universitarios de su época. Llegó a ser rector de la Universidad Central y miembro de dos Reales Academias, Historia y Ciencias Morales y Políticas. Fue historiador riguroso que sacó a la luz cientos de documentos para sus variados estudios, investigando en todo tipo de archivos. Sus trabajos se centran fundamentalmente en historia de Aragón e historia religiosa de España, si bien destacó en otra materia, el derecho eclesiástico, y como editor de diversas obras históricas.
\end{abstract}

Palabras clave: Aragón; Bibliografía; Historiografía; Real Academia de Ciencias Morales y Políticas; Real Academia de la Historia; Teología.

\section{Vicente de la Fuente y Bueno, prototype of historian and nineteenth-century investigator}

\begin{abstract}
This paper analyses the character of Vicente de la Fuente y Bueno, theologian, Catholic apologist, University professor and academic, one of the leading of $19^{\text {th }}$ century Spanish historians, and a person with a huge prestige within the academic and university environments of his age. He reached the post of Rector at Madrid Central University and was appointed as a member of two Royal Academies, History and Moral and Political Sciences. He was a deep and serious historian, who dug out hundreds of documents for his various works, searching in all kind of archives. His works deal mainly with history of Aragón and Spanish religious history, albeit he also stood out in another matter, Ecclesiastical law, and as the editor of several historical works.
\end{abstract}

Keywords: Aragón; Bibliography; Historiography; Royal Academy of History; Royal Academy of Moral and Political Sciences; Theology.

\section{INTRODUCCIÓN}

Vicente de la Fuente ocupa merecidamente un puesto relevante junto a otros grandes historiadores españoles del siglo XIX como José Amador de los Ríos, Modesto Lafuente, Pascual de Gayangos o Francisco Codera, todos ellos miembros de la Real Academia de la Historia. Si bien muchos de ellos han 
quedado injustamente olvidados y sus obras superadas, algunas de estas siguen siendo válidas por la enorme cantidad de fuentes que manejaron y por lo que supusieron en cuanto a novedad investigadora y tratamiento de la documentación. Por otro lado, estos historiadores solo son recordados en sus centenarios y ocasionalmente en sus lugares de origen.

Vicente de la Fuente fue un hombre de múltiples intereses y autor de una gran obra historiográfica. El presente trabajo recopila y analiza lo fundamental de su bibliografía, que puede dividirse en obra histórica, teológica y aragonesa, aporta los datos de los expedientes de las principales instituciones de las que fue miembro, a saber, la Universidad Central, la Real Academia de la Historia y la Real Academia de Ciencias Morales y Políticas, y su actividad en las mismas. La bibliografía sobre este ilustre personaje no es especialmente abundante; la más antigua, muy cercana a su muerte, está más centrada en alabar su figura intelectual que en analizar su obra historiográfica. Como referencias más modernas cabe citar que aparece en diversos diccionarios biográficos, en algún artículo monográfico y en obras generales de política y religión.

\section{PRIMEROS PASOS E INSTALACIÓN EN MADRID}

Vicente de la Fuente y Bueno ${ }^{1}$ nació en Calatayud el 29 de enero de 1817, fueron sus padres José de la Fuente y Felícitas Condón (Vicente y Guerrero, 2000:756-758); estudió Humanidades en los Escolapios de Daroca y Zaragoza, y Filosofía en el Seminario Conciliar de Tudela (1828-1831). Obtuvo el título de Bachiller en Filosofía por la Universidad de Zaragoza en 1831, tras lo cual pasó a estudiar teología en Alcalá de Henares, donde se licenció en 1837 se doctoró en 1841. Culminó su formación con el título de Licenciado en Derecho Canónico y Teología por la Universidad Central de Madrid en 1844, y de Doctor en Derecho en 1846. En 1844 ingresó en el Colegio de Abogados de Madrid. Además de teología y leyes, estudió con competencia árabe y hebreo.

Unos años antes, en 1837, comenzó su carrera docente al dar clases de Escritura en el Colegio de Málaga, uno de los centros que integraban la Universidad de Alcalá, y del que fue rector entre 1838 y $1842^{2}$. De aquellos años datan sus primeros artículos periodísticos, publicados en el Semanario Pintoresco Español que dirigía Mesonero Romanos, así como sus colaboraciones en la obra

${ }^{1}$ Su segundo apellido era Condón, pero lo cambió por el de Bueno, y así aparece en todas sus obras. Es por ello que en la presente biografía se mantiene el apellido elegido por él. Los diccionarios modernos, en cambio, le presentan como Vicente de la Fuente y Condón.

${ }^{2}$ El verdadero nombre del centro era Colegio Menor de San Ciriaco y Santa Paula. Algunos de sus biógrafos confunden este colegio de Alcalá con el Seminario de Málaga, donde nunca dio clase. Tras el traslado de la Universidad a Madrid, el centro pervivió como colegio universitario hasta 1843. 
costumbrista Los españoles pintados por sí mismo. Posteriormente ocupó el puesto de profesor de Ciencias Eclesiásticas en el Instituto de San Isidro de Madrid (1844), y fue sustituto en la Facultad de Derecho de la Universidad Central, en la que ejerció además como Bibliotecario Mayor interino desde 1845, encargándose del traslado de 20.000 volúmenes de la biblioteca de la Universidad de Alcalá a la Central, en 1848 (Peiró, 2002: 263-265), abierta al público en enero de 1849. Diversas circunstancias le impidieron obtener un puesto fijo en la Universidad, por lo que estuvo a punto de abandonar Madrid y aceptar un puesto eclesiástico en su villa natal (Francisco Olmos, 1992: 227-232).

Al margen de la Universidad, dio clases en la Real Academia de Legislación en 1845 , donde también ocupó los puestos de bibliotecario noviembre de 1844 enero de 1846, y presidente de la sección de Derecho civil (1846).

Finalmente logró plaza de Catedrático de Derecho Canónico en la Universidad de Salamanca, permaneciendo allí entre 1852 y 1858 , para pasar posteriormente a la Central, donde ejerció como docente titular de la misma materia desde 1858 hasta su muerte; llegó a ser Rector de la Universidad Central al iniciarse la Restauración, entre abril de 1875 y julio de 1877, cargo al que renunció como protesta ante la no readmisión de algunos catedráticos expulsados por el marqués de Orovio $^{3}$ en la llamada "Segunda Cuestión Universitaria". Ocupó también el puesto de decano interino de la Facultad de Derecho desde 1882, que le correspondía por antigüedad, y decano en propiedad en 1885. Persona más apta para el estudio y la enseñanza, se sintió mucho más cómodo en su cátedra que en los diversos puestos directivos que le tocó desempeñar. Además de Derecho Canónico, impartió también clases de Historia Eclesiástica entre 1870 y 1874 en los célebres Estudios Católicos de Madrid.

\section{LA RELIGIÓN, ASPECTO FUNDAMENTAL DE SU IDEOLOGÍA}

Cercano al carlismo en su juventud, Vicente de la Fuente era de ideología profundamente católica y conservadora, y ya en la Restauración militó en la Unión Católica de su antiguo alumno y amigo Alejandro Pidal, más por ruegos de éste que por verdaderas ambiciones políticas, que nunca tuvo. Incluso, presentado por sus amigos, llegó a ser candidato al Senado por la Universidad de Salamanca, alegrándose sinceramente de no haber sido elegido.

\footnotetext{
${ }^{3}$ Manuel Orovio Echagüe, marqués de Orovio, fue Ministro de Fomento en 1875, y emitió una circular que derogaba la libertad de cátedra y supuso el cese de diversos catedráticos universitarios.

${ }^{4}$ Gumersindo de Azcárate, uno de los catedráticos afectados y académico de Morales y Políticas en 1891, dijo a la familia en el entierro de D. Vicente: "Quiero tributar este último homenaje al hombre recto y bueno que supo cumplir siempre lo que creía su deber". Cita tomada de López Landa (1935).
} 
Participó activamente en las asociaciones religiosas y benéficas de las que formó parte. Fue cofundador en 1849, junto a Santiago Masarnau y Anselmo Ouradou, de la primera Conferencia de San Vicente de Paúl, creada en la iglesia de San Sebastián de Madrid, y colaboró asiduamente en sus "Lecturas populares", entre 1856 y 1867; fue miembro de la Academia de San Miguel, fundada en 1859 por el padre Claret contra la propagación de libros e ideas equivocadas y cuyo complemento editorial era la Biblioteca Popular y Parroquial. También formó parte desde sus inicios de la Asociación de Católicos de España, creada en 1868 en la casa del marqués de Viluma, de la que también eran miembros distinguidas personalidades neocatólicas como Santiago de Tejada, Aparisi y Guijarro, Carbonero y Sol o Cándido Nocedal, y cuya misión era defender la unidad católica del Estado ante la deriva antirreligiosa de la revolución, favorecer misiones, abrir escuelas parroquiales y luchar contra el proselitismo protestante. Además colaboró asiduamente en la prensa católica, apareciendo multitud de artículos firmados por él en El Conciliador ${ }^{5}$, donde colaboró con Balmes y José María Quadrado, Boletín del Clero Españo" ", La Cruz, La Cruzada, La Unidad Católica, El Altar y el Trono, La Ilustración Católica o Calendario piadoso, publicación en la que se encargaba, con tono jocoso e irónico, de la crónica contemporánea.

Alejandro Pidal dijo de él que "Su vida era la de un hombre de bien que practica lo que profesa. Se levantaba con el día, recibía el pan de los ángeles diariamente, se confortaba con la oración, visitaba a sus pobres, desempeñaba sus trabajos de cátedra y Academias, comía a las dos, dormía siesta de tres a cuatro, y el resto lo consagraba al estudio. No trasnochaba jamás, y no se sabe de nadie que le viera en ningún teatro" (Pidal, 1898: 347).

Por si pudiera haber dudas de su catolicismo, dejó en su testamento, después de la más fervorosa indicación de su fe católica, la siguiente cláusula: "Y como quiera que tiene escritas y publicadas algunas obras de Derecho Canónico, Historia, Disciplina y otras ciencias eclesiásticas en que pudiera haber alguna equivocación material o frase que se pudiera tomar en mal sentido, desde ahora para siempre las retracta en cuanto se pudieran tomar en ese mal sentido; y se somete en eso, como en todo, a lo que disponen o dispusieren la Santa Sede y Prelados de la Iglesia; y es mi voluntad que los testamentarios lo hagan constar en la forma que tuvieren por conveniente"7. Por su parte, decían los carlistas: "Aquí

${ }^{5}$ Periódico de muy corta vida en el que Balmes y Quadrado defendían la conveniencia del matrimonio entre Isabel II y el conde de Montemolín. Recoge algunos de los escasos artículos políticos de Vicente de la Fuente.

${ }^{6}$ Se encargó, por ejemplo, del Boletín del Clero de 1850, que incluía las biografías y retratos de los señores prelados actuales de la iglesia de España, y la necrología de los individuos más notables del clero fallecidos en dicho año (Madrid, 1851).

${ }^{7}$ Según la carta remitida por su hermano a la Real Academia de Ciencias Morales y Políticas y conservada en su expediente. 
solo cabe ser católico o afiliándose al partido tradicionalista, o siendo como don Vicente de la Fuente",.

No es de extrañar, por tanto, que su amplísima y polifacética producción bibliográfica esté muy influida por su acendrado catolicismo, si bien rechazaba todo tipo de supersticiones religiosas, que consideraba dañinas para la fe. Hay que destacar, asimismo, el perfil histórico con el que presenta sus trabajos, aún aquellos de materias tan áridas como el derecho eclesiástico.

\subsection{OBRAS TEOLÓGICAS Y RELIGIOSAS}

Artículos periodísticos aparte, su tarea de escritor comenzó en 1842, con la traducción libre del francés y la publicación de Observaciones sobre el protestantismo [Discurso compuesto para leerlo en el consejo del rey de Francia por un ministro amante de su patria] (Madrid, 1842), obra a la que añadió una reflexión propia sobre los resultados que tendría el protestantismo en España. En contra de esa religión escribió el folleto El tercer jubileo del Santo Concilio de Trento: Comparación entre el Catolicismo y el Protestantismo (Madrid, 1863), y los opúsculos de la serie "El protestante protestado" titulados Andrés Tunn (Madrid, 1869) y La muerte feliz, o sea refutación del folleto protestante del mismo título, y de otro que lleva el epígrafe de "Camino seguro" (Madrid, 1869).

Fue autor y editor de importantes obras sobre derecho y disciplina eclesiástica, su gran especialidad jurídica: Discurso acerca de la validez canónica de los grados académicos conferidos en España en estos últimos tiempos (Madrid, 1850); se encargó de publicar el Compendium Theologiae dogmaticae et moralis (Madrid, 1864), del capuchino Tomás de Charmes'; escribió La retención de bulas en España ante la Historia y el Derecho (Madrid, 1865, 2 vol.), obra que contiene un tratado sobre la prohibición de libros y el índice expurgatorio, y La pluralidad de cultos y sus inconvenientes (Madrid, 1865); escribió también División de poderes: Estudios filosófico-canónicos sobre las relaciones entre la Iglesia y el Estado (Madrid, 1866), tema sobre el que volvería a insistir en su discurso de ingreso en la Real Academia de Ciencias Morales y Políticas.

Otras obras sobre derecho eclesiástico son el estudio Los concordatos: Cuestiones de derecho público eclesiástico sobre su revocabilidad (Madrid, 1872); el manual de derecho canónico titulado Ecclesiasticae disciplinae lectiones, ex Sacro Tridentino Concilio, necnon ex hispanis synodis et conventionibus (Madrid, 1877), Tratado teórico-práctico de procedimientos eclesiásticos

${ }^{8}$ Cita tomada de López Landa (1935), p. 37

9 Tomás de Charmes (1703-1765), teólogo y filósofo francés, catedrático de historia eclesiástica y autor de la magna obra Theologia Universa (Nancy, 1750), muy leída y utilizada en los siglos XVIII y XIX. 
(Madrid, 1868, 4 vol.), del que fue coautor su amigo Francisco Gómez Salazar, futuro obispo de León, y con el que también publicó Lecciones de disciplina eclesiástica (Madrid, 1876, 2 vol.) Impartió asimismo una conferencia en la Academia Jurídica sobre El divorcio (Madrid, 1880), asunto en el que eran entonces competentes las autoridades eclesiásticas.

Sobre la beneficencia y la actividad asistencial de la Iglesia, asuntos en los que estuvo muy implicado, escribió la obra La sopa de los conventos, o sea Tratado de economía política en estilo joco-serio acerca de los obstáculos tradicionales en nuestro país (Madrid, 1868) ${ }^{10}$.

La historia, tanto general como eclesiástica, fue otro de sus grandes temas de interés, destacando al respecto la Historia eclesiástica de España ${ }^{11}$ (Barcelona, 1855-1859, 4 vol.), obra que tuvo una excelente acogida y hubo de ser reimpresa y adicionada (Madrid, 1873-1875, 6 vol.), la Vida de la Virgen María, con la historia de su culto en España (Barcelona, 1877-1879, 2 vol.), una de sus mejores obras religiosas; La Vizcondesa de Jorbalán en el claustro la Madre Sacramento, fundadora del Instituto de Adoratrices del Santísimo ${ }^{12}$ (Madrid, 1884); y La expulsión de los jesuitas de España en 1767: colección de artículos publicados el año de 1867 en la revista católica La Cruzada (Madrid, 1868).

Una de sus principales obras es Historia de las sociedades secretas, antiguas y modernas en España y especialmente de la francmasonería (Lugo, 1870-1871, 3 vol.), a la que consideraba origen de todas las sediciones y pronunciamientos acaecidos en nuestro país, y para la que recabó todas las fuentes que pudo, si bien era consciente de lo poco que había escrito sobre la materia y de lo desacreditada que estaba la masonería española.

Especialmente devoto de Santa Teresa, publicó y anotó los Escritos de Santa Teresa de Jesús, que conforman el tomo 53 de la Biblioteca de Autores Españoles (Madrid, 1861-1862, 2 vol.); se ocupó igualmente de editar la obra inédita del maestro Julián de Ávila ${ }^{13}$ Vida de Santa Teresa de Jesús (Madrid, 1881), así como de una nueva edición del Libro de las Fundaciones ${ }^{14}$ (Madrid, 1880), incluyendo el texto facsímil del manuscrito conservado en El Escorial, y finalmente escribió El Tercer centenario de Santa Teresa de Jesús: Manual del peregrino para visitar

${ }^{10}$ Esta obra ha sido reeditada en 2013 por la Institución Fernando el Católico de Zaragoza.

${ }^{11}$ Esta obra lleva como subtítulo Adiciones a la Historia general de la Iglesia, escrita por Alzog; se refiere a la Histoire universelle de l'Église de Johannes B. Alzog (Paris, 1845-1847, 3 vol.)

${ }^{12}$ Se trata de una biografía de Micaela Desmaissières y López de Dicastillo (1809-1865), aristócrata española que en 1845 fundó las Adoratrices del Santísimo Sacramento y fue beatificada con el nombre de Santa María Micaela del Santísimo Sacramento.

${ }^{13}$ Julián de Ávila (1527-1605) fue servidor y primer capellán de Santa Teresa.

${ }^{14}$ Edición que él mismo financió y que supuso un considerable fracaso económico. 
la patria, sepulcro y parajes donde fundó la Santa o existen recuerdos suyos en España (Madrid, 1882) ${ }^{15}$.

Antes de morir participó en el primer Congreso Católico Nacional Español, celebrado en la iglesia de los Jerónimos de Madrid en los meses de abril y mayo de 1889 , en el que pronunció sendos discursos sobre dos instituciones que conocía bien: la Asociación de Católicos y las Hermanas de Santa Ana para convalecientes ${ }^{16}$.

\section{VICENTE DE LA FUENTE EN LA REAL ACADEMIA DE LA HISTORIA}

Sus buenas dotes como historiador, demostradas especialmente en su Historia eclesiástica de España (4 vol.), le valieron ser elegido académico numerario de la Real Academia de la Historia en 1860, a la que ya pertenecía como correspondiente desde $1854^{17}$, avalando su candidatura Felipe Canga-Argüelles, Cayetano Rosell y Pascual Gayangos. Ocupó la medalla $n^{\circ} 34$, vacante por el fallecimiento del conde de Quinto. Su discurso de ingreso, leído el 16 de marzo de 1861, llevó por título Historia militar, política y económica de las tres comunidades de Calatayud, Daroca y Teruel y la contestación corrió a cargo de Manuel Colmeiro.

En este discurso, primero de sus trabajos sobre historia de Aragón, dio a conocer las Comunidades de Aragón, un tema poco tratado y peor conocido. Su origen se remonta al siglo XII, y el nuevo académico se centró en su aspecto militar, político y económico. Como muestra de su excelente manejo de todo tipo de fuentes jurídicas e históricas, añadió una serie de nueve apéndices sobre las tres comunidades descritas: Designación de términos a las Comunidades, según los fueros de Calatayud, Daroca y Teruel; Bula del Papa Lucio III aprobando la patrimonialidad de las iglesias de Calatayud y su Comunidad; Privilegio de Doña Leonor en 1218; Hermandad entre varios pueblos de Aragón; Asistencia de los Procuradores de las Comunidades a las Cortes de Aragón; Derogación del Fuero de Teruel y su comunidad por Felipe III; Organización judicial y administrativa de las Comunidades; Preámbulo de las ordenanzas de la Comunidad de Daroca, por el rey Felipe V; Pueblos de las tres comunidades y su estadística comparada, según el censo de 1797.

Por otro lado, el mismo año de su ingreso, la Academia le nombró individuo de la Comisión de España Sagrada, de la que también formaron parte Carlos Ramón

${ }^{15} \mathrm{Su}$ último trabajo sobre la santa es Avileses célebres inscritos en el monumento a Santa Teresa de Jesús en Ávila (BRAH, IV, cuad. IV, 1884)

${ }^{16}$ Crónica del Primer Congreso Católico Nacional Español: Discursos pronunciados en las sesiones públicas de dicha asamblea. Madrid, 1889, p. 398 y 414

${ }^{17} \mathrm{Su}$ candidatura como académico correspondiente fue firmada por Pedro Sabau, Antonio Delgado, Antonio Cavanilles y José Amador de los Ríos. 
Fort, Juan Manuel Montalbán y José Oliver Hurtado ${ }^{18}$; asimismo le designó para que la representase en el Congreso Arqueológico de Amberes de 1867, y le nombró miembro de la Comisión de Cortes y Fueros. También formó parte de la Comisión mixta de académicos de la Historia y de Bellas Artes encargada de organizar las Comisiones Provinciales de Monumentos Artísticos e Históricos. Como miembro de la primera Comisión citada, se ocupó de la edición de los tomos 49 al 51 de la España Sagrada ${ }^{19}$, dos de ellos de tema específicamente aragonés.

Como puede observarse, se incorporó rápida y eficazmente a las actividades académicas, y ya en 1862 leyó un Elogio del Arzobispo D. Rodrigo Jiménez de Rada y juicio crítico de sus escritos históricos (Madrid, 1862), personaje histórico por el que sentía especial interés y sobre el que publicó más trabajos en el Boletín, concretamente sobre sus restos mortales y su sepulcro en el monasterio de Santa María de Huerta ${ }^{20}$. Se ocupó también de los discursos de contestación de dos académicos recipiendarios, el militar Jacobo de la Pezuela y Lobo ${ }^{21}$, y el gran arabista Francisco Codera y Zaidín ${ }^{22}$.

Por encargo igualmente de la Academia de la Historia publicó la obra del capitán Gonzalo Fernández de Oviedo y Valdés Las quinquagenas de la nobleza de España (Madrid, 1880), y emitió una treintena de informes de temática variada: recensiones de libros, arte, arqueología, Derecho, antigüedades... ${ }^{23}$ Destacan al respecto dos recensiones sobre sendas obras enviadas a la Academia: Descripción histórica, artística, detallada y circunstanciada de la ciudad de Alcañiz y sus afueras, de Nicolás Sancho (Alcañiz, 1860), e Historia de Valladolid, de Juan Antolínez de Burgos (Valladolid, 1887).

${ }^{18}$ La misión de la Comisión era continuar la magna obra iniciada por el padre Flórez en el siglo XVIII.

${ }^{19}$ El t. 49 (1865) está dedicado a La Santa Iglesia de Tarazona en sus estados antiguo y moderno; el 50 (1866) a Las Santas Iglesias de Tarazona y Tudela en sus estados antiguo y moderno; el 51 (1879), obra póstuma de Carlos Ramón Fort, trata De los Obispos españoles titulares de Iglesias in partibus infidelibus o auxiliares en las Españas, y fue coordinado y aumentado por la Fuente.

${ }^{20}$ Boletín de la Real Academia de la Historia, VI, cuad. II, 1885; Ídem, X, cuad. III, 1887;Ídem, X, cuad. IV, 1887

${ }^{21}$ PEZUELA Y LOBO, J. (1866): Historia del gran imperio colonial que, por espacio de tres siglos, poseyó España al otro lado del Atlántico; discurso leído en el acto de su recepción en la Real Academia de la Historia, y contestación de D. Vicente de la Fuente.

${ }^{22}$ CODERA Y ZAIDÍN, F. (1879): Dominación arábiga en la frontera superior, 711 a 815; discurso leído en el acto de su recepción en la Real Academia de la Historia, y contestación de D. Vicente de la Fuente.

${ }^{23}$ Así, p. ej., El fuero de Nájera (Boletín de la Real Academia de la Historia, I, cuad. III, 1879); Historia de la instrucción pública en Portugal, por Antonio da Costa (Ídem, III, cuad. II, 1883) o El Cartulario del Monasterio de Eslonza (Ídem, IX, cuad. V, 1886) 


\section{VICENTE DE LA FUENTE EN LA REAL ACADEMIA DE CIENCIAS MORALES Y POLÍTICAS}

Por lo que respecta a su paso por la Real Academia de Ciencias Morales y Políticas (RACM), resultó elegido el 20 de enero de 1874 para la medalla $\mathrm{n}^{\mathrm{o}} 34$, vacante por el fallecimiento de Cirilo de Alameda y Brea. Fue propuesto por los académicos Antonio Benavides, Fernando Álvarez, Claudio Moyano, Santiago de Tejada, Fermín Caballero y Manuel Colmeiro ${ }^{24}$, y en su elección pesaron su prestigio y su vasta erudición en una materia tan importante entonces como era el derecho eclesiástico. Su discurso de ingreso, leído el 25 de abril de 1875, llevó por título De la separación de la Iglesia y el Estado, ocupándose de la contestación Manuel Colmeiro, quien ya hizo lo propio en la Academia de la Historia.

En aquel tiempo, uno de los temas que más preocupaba y que ocasionaba encendidas discusiones en los centros intelectuales era la conciliación de la razón humana con la fe católica y las relaciones entre la Iglesia y el Estado. En una época en que las nuevas corrientes filosóficas iban extendiéndose aceleradamente no podía faltar la réplica de los sectores más tradicionalistas. Este asunto tuvo gran importancia en los debates intelectuales del último cuarto del siglo XIX, y así quedó reflejado en los discursos de ingreso de no pocos académicos recipiendarios y en diversas discusiones habidas en el seno de la Academia. En efecto, desde una cosmovisión católica y conservadora, como la que dominaba el mundo intelectual de entonces, se analizaron las nuevas tendencias y sus fundamentos, muchas veces apoyados en el racionalismo. Este racionalismo, del que nacía la modernidad, abarcaba las más diversas áreas del conocimiento: filosofía, política, economía... con lo que el espacio religioso se reducía a pasos agigantados, con la consiguiente preocupación de los sectores conservadores. A este respecto, conviene resaltar que desde su fundación se leyeron en la Academia varios discursos de ingreso con la misma temática de fondo y haciendo patentes estas preocupaciones ${ }^{25}$.

El discurso de D. Vicente entra de lleno en esta polémica; así, tras explicar cómo el Estado se ocupa de asuntos que le son propios por derecho y por deber,

${ }^{24}$ Expediente del Excmo. Sr. D. Vicente de la Fuente. Archivo de la Real Academia de Ciencias Morales y Políticas.

${ }^{25}$ Por ejemplo: SANZ LAFUENTE, M. (1860): Influencia de la moral cristiana en nuestra civilización e impotencia de la moral filosófica para obtenerla; ANDONAEGUI, J.A. (1869): Demostración de que en la religión católica el criterio de la verdad no es la razón natural, sino la autoridad de la Iglesia docente; MORENO NIETO, J. (1879): Oposición fundamental entre la civilización religioso-cristiana y la racionalista; ORTÍ Y LARA, J.M. (1899): Teorías opuestas entre sí acerca del Estado y su fin, según que procedan del concepto de la evolución o del concepto de la creación; PERIER Y GALLEGO, C. (1881): La armonía en la civilización es el gran problema que este siglo crítico, gigante en lo material, pero incierto en lo filosófico y flaco en lo moral, lega al siglo siguiente. 
dice que este no tiene la misma competencia en asuntos religiosos y espirituales, en los que la superioridad de la Iglesia es indiscutible. En una época de transición como la actual, prosigue el nuevo académico, se suelen pretender curar los antiguos extravíos con errores nuevos, y entre ellos descuella la separación completa de la Iglesia y el Estado, idea copiada de los Estados Unidos que no tiene cabida en los países católicos latinos. Es una política adecuada para los países protestantes que tienen multiplicidad de iglesias y sectas; pero la anarquía en materia de religión que ello provoca trasciende a la moral pública y privada. Estas ideas separatistas, que rompen la armonía entre la Iglesia y el Estado, son producto de la indiferencia religiosa y el ateísmo social, y su triunfo supone la proclamación del ateísmo oficial. A lo largo de la historia, todos los intentos de emancipación han conducido a guerras y catástrofes. España, por su parte, miró siempre a la Iglesia como a una madre santa, lo que explica el autor con abundantes ejemplos históricos, para concluir diciendo que él quiere una política católica y no un catolicismo político maníaco. Al igual que hizo en su discurso de ingreso en la Academia de la Historia, en esta ocasión añadió otros tantos apéndices de diversas fuentes históricas y jurídicas en apoyo de su tesis, así como alocuciones papales y exposiciones sobre el cesarismo, regalismo y civilismo; cierra este conjunto documental el proyecto de separación entre la Iglesia y el Estado que presentó a las Cortes el poder ejecutivo de la República Federal en 1873, y que D. Vicente se encarga de desmontar artículo por artículo.

Irónicamente, su discurso de ingreso fue comentado, con ánimo de crear polémica, por el diario ultracatólico El Siglo Futuro ${ }^{26}$, que publicó una serie de artículos recogidos bajo el título El ascetismo liberal (1875), lo que provocó la respuesta de Vicente de la Fuente con el opúsculo titulado Exposición de las palabras secularización, emancipación y separación al tratar de las relaciones entre la Iglesia y el Estado (Madrid, 1876). Decía el nuevo académico "que el objeto de la Iglesia era el bien común de la Iglesia y el Estado, por medio de sus buenas y armónicas relaciones, y cada uno con independencia en su esfera de acción" ${ }^{27}$, algo que los articulistas del periódico interpretaron como que "el catolicismo liberal pretende fundar un sistema medio, moderado, entre la doctrina puramente católica, que subordina el Estado a la Iglesia, y la puramente herética, que reduce la Iglesia a una dependencia del Estado, y esta doctrina medio católica, es precisamente la del Sr. La Fuente" ${ }^{28}$. La doctrina de Vicente de la Fuente sobre este asunto era la del Papa León XIII, que a su vez fue la de todos los teólogos y

${ }^{26}$ Dirigido inicialmente por Cándido Nocedal, de orientación carlista y abonado a las polémicas en el seno del ultracatolicismo, este periódico llegó a acusar de veleidades liberales a los obispos españoles de la Restauración.

${ }^{27}$ De la separación de la Iglesia y el Estado, p. 32.

${ }^{28} \mathrm{El}$ ascetismo liberal, p. 36. 
canonistas del Siglo de Oro español e incluso la de un alto cargo de la Iglesia nada sospechoso de liberal como fuera a principios de siglo el cardenal Inguanzo ${ }^{29}$.

Durante los casi 15 años que fue académico se le contabilizaron 555 asistencias y ocupó el cargo de censor entre 1878 y 1889. En 1883, y por ausencia del Secretario, se encargó de leer el Resumen de las Actas de la Real Academia de Ciencias Morales y Políticas ${ }^{30}$, que realmente fue el discurso conmemorativo de los veinticinco años de la Academia, fundada en 1857. Se encargó asimismo de contestar a los discursos de ingreso del catedrático de economía Melchor Salvá y Hormaechea $^{31}$, y de tres sacerdotes elegidos académicos en esa década de los años 80: Francisco J. Caminero y Muñoz ${ }^{32}$, Francisco Gómez de $\mathrm{Salazar}^{33}$ y José Salamero y Martínez ${ }^{34}$. Los discursos de estos religiosos abundan en la misma temática de la crisis religiosa de la sociedad y en la insuficiencia de la filosofía para dar respuesta a los problemas del mundo moderno.

Por otra parte, leyó en 1880 dos memorias en sendas sesiones académicas sobre "establecimientos caritativos para la corrección de jóvenes indóciles y extraviadas", como eran Los Toribios de Sevilla, y Las Adoratrices ${ }^{35}$, tema que luego amplió en un libro sobre la fundadora de las Adoratrices ${ }^{36}$. En otra sesión de febrero de 1885 se encargó de analizar y defender las obras del Abate y filósofo italiano Antonio Rosmini (1797-1855), que habían levantado, como es sabido, una agria polémica en Italia ${ }^{37}$.

${ }^{29}$ Vid. CUENCA TORIBIO, J.M.: D. Pedro de Inguanzo y Rivero (1764-1836): último primado del Antiguo Régimen. Pamplona, Universidad de Navarra, 1965.

${ }^{30}$ Memorias de la RACM, t. V (1884), p. 1 y ss.

31 SALVÁ Y HORMAECHEA, M. (1880): Expresión de las ideas económicas en la literatura; discurso leído en el acto de su recepción en la Real Academia de Ciencias Morales y Políticas, y contestación de D. Vicente de la Fuente.

${ }^{32}$ CAMINERO Y MUÑOZ, F.J. (1881): La filosofía disidente, en lo que tiene de tal, no puede darnos la verdad; y en sus aplicaciones a las ciencias morales y políticas no puede darnos el bien; discurso leído en el acto de su recepción en la Real Academia de Ciencias Morales y Políticas, y contestación de D. Vicente de la Fuente.

${ }^{33}$ GÓMEZ DE SALAZAR, F. (1885): Relaciones entre la Iglesia y el Estado o Etnarquía cristiana; discurso leído en el acto de su recepción en la Real Academia de Ciencias Morales y Políticas, y contestación de D. Vicente de la Fuente.

${ }^{34}$ SALAMERO MARTÍNEZ, J. (1890): La crisis religiosa, causa principalísima de la crisis social, tiene en el catolicismo su remedio más eficaz; discurso leído en el acto de su recepción en la Real Academia de Ciencias Morales y Políticas, y contestación de D. Vicente de la Fuente. Esta contestación fue leída por Alejandro Pidal, pues Vicente de la Fuente falleció unos meses antes.

${ }^{35}$ Memorias de la Real Academia de Ciencias Morales y Políticas (RACM), t. V (1884), p. 329-349 y 351-370.

${ }^{36}$ Vid. nota 12.

${ }^{37}$ Memorias de la RACM, t. VI (1889), p. 643 y ss. 
También en el seno de esta Academia, poco antes de su muerte, tuvo tiempo para demostrar sus dotes de historiador, y a lo largo de tres sesiones que tuvieron lugar en noviembre de 1889 disertó sobre La Constitución política de Aragón en el año $1300^{38}$, que aunque comienza con los fueros otorgados por el rey Jaime II, es un completo estudio de la historia constitucional aragonesa. Finalmente, en uno de los escasos trabajos en que se aparta de sus temas corrientes, presentó un informe sobre la obra Exposición del Código Penal venezolano, de Francisco Ochoa (Maracaibo, $1888)^{39}$, que había sido remitida a la Academia para que emitiera su opinión.

\section{OTRAS OBRAS}

Por otro lado, de sus escritos sobre historia aragonesa, además de la continuación de la España Sagrada, su discurso de ingreso en la Real Academia de la Historia, y la memoria leída en la Real Academia de Ciencias Morales y Políticas, hay que mencionar la Historia de la siempre augusta y fidelisima ciudad de Calatayud (Madrid, 1880-1881, 2 vol. $)^{40}$, obra más erudita que divulgadora acompañada de docenas de documentos, Las Comunidades de Castilla y Aragón bajo el punto de vista geográfico (Madrid, 1880), trabajo publicado por la Real Sociedad Geográfica, los Estudios críticos sobre la historia y el derecho de Aragón (Madrid, 1884, 3 vol.), que son una recopilación y análisis crítico de diferentes episodios de la historia aragonesa, abarcando desde Sancho el Mayor a Fernando el Católico, y algunos trabajos más publicados en el Boletín de la Real Academia de la Historia (BRAH) ${ }^{41}$.

Del resto de su bibliografía histórica tiene especial interés el Programa razonado de lecciones de crítica histórica explicadas en el Círculo de la Unión Católica (Madrid, 1883), y una serie de estudios biográficos: Biografía de León de Castro $^{42}$ (Madrid, 1860), Doña Juana la Loca, vindicada de la nota de herejía (Madrid, 1869), y Palacios Rubios: su importancia jurídica, política y literaria ${ }^{43}$

${ }^{38}$ Memorias de la RACM, t. VII (1893), p. 167 y ss.

${ }^{39}$ Memorias de la RACM, t. VII (1893), p. 413 y ss.

${ }^{40}$ Esta obra sobre su ciudad natal no recibió muy buenas críticas, pues si bien supuso un considerable acopio de fuentes y materiales varios, la escribió con precipitación y contiene muchos errores.

${ }^{41}$ Noticia acerca de un edificio romano que se conserva en las inmediaciones de la villa de Fabara, partido de Alcañiz (BRAH, I, cuad. V, 1879); San Juan de la Peña (BRAH, XIV, cuad. IV, 1889); El último Justicia de Aragón en 1710 (BRAH, XIV, cuad. V, 1889); Archivos de Tarazona, Veruela, Alfaro, Tudela, Calatayud y Borja (BRAH, XXIV, cuad. III, 1894), este último publicado póstumamente.

${ }^{42}$ Dominico y helenista español del siglo XVI.

${ }^{43}$ Se refiere a Juan López de Palacios Rubios (1450-1524), uno de los juristas que justificó la conquista y colonización de América. 
(Madrid, 1869). Cabe destacar, por último, su colaboración en la empresa editorial de Daniel Cortezo "España y sus monumentos", y para la que escribió, en colaboración con José María Quadrado, los tomos correspondientes a las provincias de Castilla la Nueva (Madrid, 1886).

Por otra parte, como persona muy docta que era en materias bibliográficas, durante su estancia en Salamanca redactó el Catálogo de los libros manuscritos que se conservan en la Biblioteca de la Universidad de Salamanca (Salamanca, 1855); allí mismo leyó la lección inaugural del curso académico 1856-1857, titulada Sobre la necesidad de Universidades en España (Salamanca, 1857), tema sobre el que volvería a escribir más adelante, como ya se ha visto.

Otro aspecto fundamental de su actividad intelectual fue el de editor literario, de lo que dio abundantes muestras a lo largo de toda su vida. Así, también para la Biblioteca de Autores Españoles, preparó la edición de las Obras escogidas de Fray Benito Jerónimo Feijoo (Madrid, 1863) y las Obras escogidas del jesuita Pedro de Rivadeneira (Madrid, 1868), incluyendo en ambos casos una breve biografía y un juicio crítico de sus escritos. Por Real Orden, y en colaboración con Pascual Gayangos publicó las Cartas de Fray Francisco Jiménez de Cisneros dirigidas a Diego López de Ayala (Madrid, 1867), obra complementada posteriormente con Cartas de los secretarios del cardenal D. Fr. Francisco Jiménez de Cisneros durante su regencia de los años 1516 y 1517 (Madrid, 1875). Otra muestra de su incansable labor de reedición de obras antiguas fue Sancti Anselmi Lucensis Episcopi vita, poema del siglo XII sobre San Anselmo II de Luca, que publicó y anotó (Madrid, 1870).

\section{RECONOCIMIENTOS}

Vicente de la Fuente había contraído matrimonio en 1861 con la navarra Eusebia Marugán. Fallecido en Madrid el día de Navidad de 1889, fue enterrado en el cementerio de la Sacramental de San Justo, si bien sus restos fueron trasladados en octubre 1922 a la Capilla de Nuestra Señora de Mediavilla, en Santa María la Mayor de Calatayud. Aprovechando la ocasión, se le tributó un homenaje en su ciudad natal el 27 de octubre de dicho año, bajo la presidencia del cardenal Juan Soldevila, primero en la Colegiata, en la que el canónigo de Zaragoza, Santiago Guallart, leyó una oración fúnebre, y posteriormente en el Teatro Principal, donde Eduardo Ibarra, académico de la Historia, leyó una necrología ${ }^{44}$. Por su parte, si bien no participó en la política de su tiempo, como se ha expuesto más atrás, Vicente de la Fuente hizo uso de todas sus influencias para que, en 1884, fuese declarada monumento nacional la antigua Colegiata de Santa María la Mayor de Calatayud, donde hoy reposan sus restos.

${ }^{44}$ Boletín de la Real Academia de la Historia, LXXXI, cuad. VI, 1922, p. 495 y ss. 
La Universidad Central, a la que tanto tiempo estuvo vinculado, le recordó a través del discurso de inauguración del curso 1891-1892, leído por el catedrático de Derecho procesal Salvador Torres, quien hace un encendido elogio de su figura docente e intelectual.

\section{CONCLUSIÓN}

Como se puede comprobar, Vicente de la Fuente es un buen ejemplo del tipo de historiadores que abundaron en la España del siglo XIX. Fue una persona muy religiosa, fiel a su ideología y totalmente consecuente con la misma; además de catedrático durante largos años, y como tal buen conocedor de los problemas universitarios, fue un infatigable escritor que destacó como investigador con múltiples intereses, y un gran erudito preocupado por rescatar del olvido antiguas obras de ilustres personajes. Nunca olvidó su Calatayud natal y aprovechó todo lo que pudo para escribir y dar a conocer la historia de Aragón. Por todo ello fue reconocido públicamente al ser nombrado rector y dos veces académico. Su obra, ciertamente envejecida, presenta todavía numerosos aspectos de interés para el investigador moderno. Es una figura que no debería caer en el olvido.

\section{REFERENCIAS BIBLIOGRÁFÍCAS}

ARCHIVO DE LA REAL ACADEMIA DE CIENCIAS MORALES Y POLÍTICAS, Expediente del Excmo. Sr. D. Vicente de la Fuente y Bueno, C 32. ARCHIVO DE LA UNIVERSIDAD COMPLUTENSE DE MADRID, Expediente personal del catedrático D. Vicente de la Fuente y Bueno, D - Ca 508.

CUENCA TORIBIO, J. M. (2002). Estudios sobre el catolicismo español contemporáneo (III). Córdoba, Universidad de Córdoba.

DIEGO GARCÍA, Emilio de (2009). 1857-2007. La Real Academia de Ciencias Morales y Políticas: Política y cultura en la España contemporánea. Madrid: Real Academia de Ciencias Morales y Políticas.

FRANCISCO OLMOS, José $\mathrm{M}^{\mathrm{a}}$ de (1992). "La vida y obra de Vicente de la Fuente", en Medievalismo: Boletín de la Sociedad Española de Estudios Medievales, $\mathrm{n}^{\circ}$ 2, pp. 227-232.

LÓPEZ LANDA, José M ${ }^{\text {a }}$ (1935). Don Vicente de la Fuente [Discurso de ingreso leído en el acto de su recepción en la Academia Aragonesa de Nobles y Bellas Artes de San Luis, el día 5 de mayo de 1935]. Zaragoza: Ed. Heraldo de Aragón.

MARQUÉS DE SIETE IGLESIAS (1978). "Real Academia de la Historia. Catálogo de sus individuos. Noticias sacadas de su Archivo. Académicos de número", en Boletín de la Real Academia de la Historia, t. 175, pp. 559-561.

PEIRÓ, Ignacio; PASAMAR, Gonzalo (2002). Diccionario Akal de historiadores españoles. Madrid: Akal. 
PIDAL, Alejandro (1898). "Necrología del Ilmo. Sr. Don Vicente de la Fuente leída ante la Real Academia de Ciencias Morales y Políticas en la sesión del 10 de junio de 1890", en Necrologías de los señores académicos de número, t. I, pp. 343-369.

TORRES AGUILAR-AMAT, Salvador (1891). Discurso leído en la Universidad central en la solemne inauguración del curso académico de 1891 a 1892. Madrid: Imprenta Colonial.

URIGÜEN, Begoña (1986). Orígenes y evolución de la derecha española: el neocatolicismo. Madrid: CISC.

VICENTE Y GUERRERO, Guillermo (2009) "Vicente de la Fuente y Condón", en Diccionario Biográfico Español, Madrid: Real Academia de la Historia, t. XX, p. 756-758. 


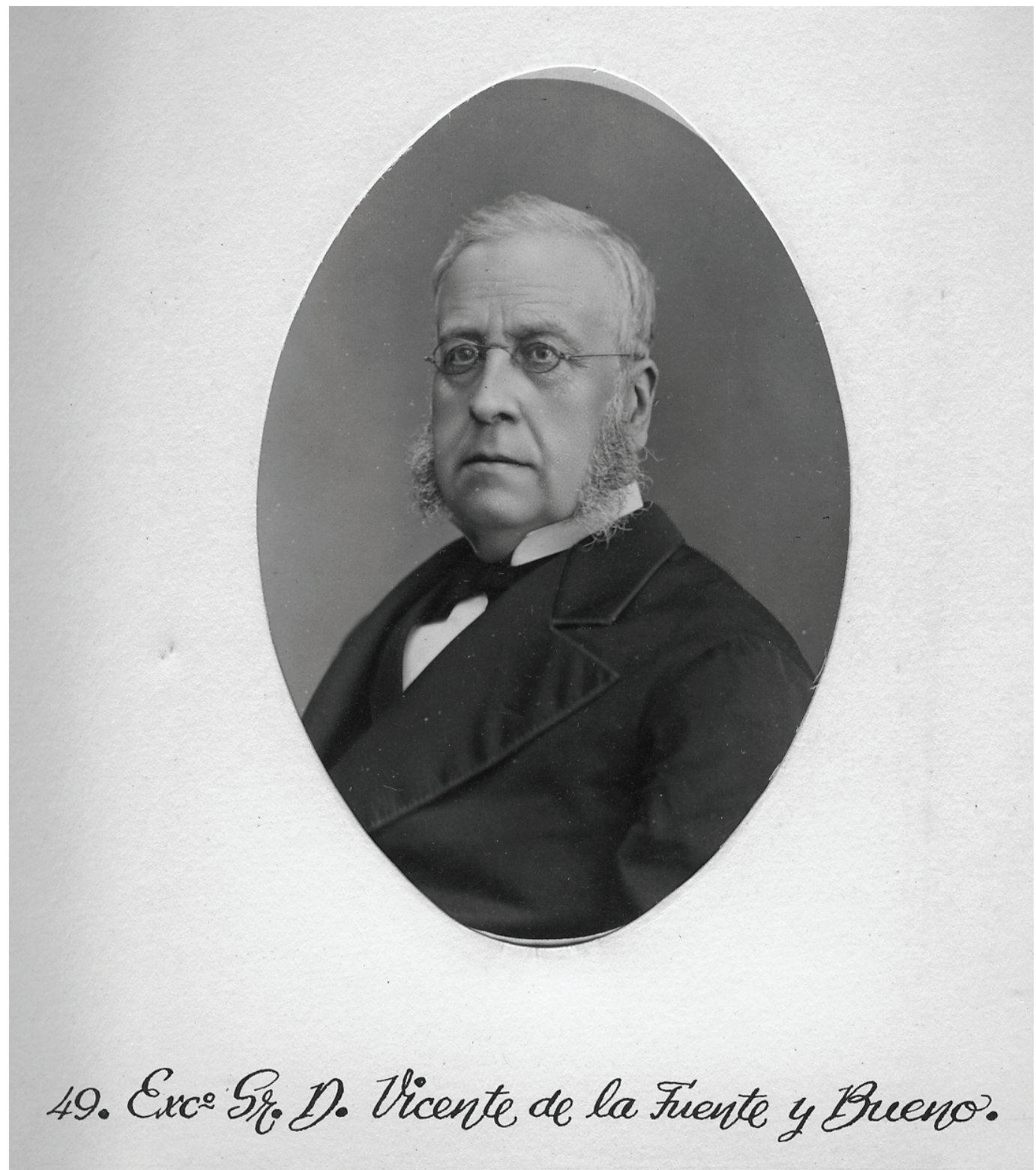

Archivo de la Real Academia de Ciencias Morales y Políticas 